Canadian

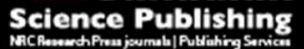

Canadian Journal of Civil Engineering Revue canadienne de génie civil

\title{
Analytical, Morphological and Rheological Behavior of Sulphur-Extended-Binder
}

\begin{tabular}{|r|l|}
\hline Journal: & Canadian Journal of Civil Engineering \\
\hline Manuscript ID & cjce-2015-0409.R1 \\
\hline Manuscript Type: & Article \\
\hline Date Submitted by the Author: & 10-Mar-2016 \\
\hline Complete List of Authors: & $\begin{array}{l}\text { Gedik, Abdul; ITU, Transportation Engineering } \\
\text { Lav, A.hilmi; lav@itu.edu.tr; Istanbul Technical University }\end{array}$ \\
\hline Keyword: & Sulphur, Bitumen, Extension, Aging \\
\hline \multicolumn{2}{|l}{} \\
\hline
\end{tabular}

SCHOLARONE $^{\text {Ix }}$

Manuscripts 


\title{
Analytical, Morphological and Rheological Behavior of Sulphur-Extended-Binder
}

\author{
Abdulgazi GEDIK ${ }^{1 *}$, Abdullah Hilmi LAV ${ }^{2}$ \\ 1 PhD Candidate, Faculty of Civil Engineering, Istanbul Technical University, Istanbul, TURKEY, \\ *Corresponding author, Tel.: +90 21228565 85, Fax: +90 21228565 87, e-mail: gedikab@hotmail.com \\ ${ }^{2}$ Professor of Civil Engineering, Faculty of Civil Engineering, Istanbul Technical University, Istanbul, TURKEY, \\ Tel.: +90 21228565 85, Fax: +90 21228565 87, e-mail: $\underline{\text { lav@,itu.edu.tr }}$
}




\title{
Analytical, Morphological and Rheological Behavior of Sulphur-Extended-Binder
}

\begin{abstract}
Bituminous material is a limited natural resource mainly used in hot mix asphalt production. The high costs coupled with the large amounts required have been forcing pavement engineers to find cost effective alternative materials that can be used as extenders or partial substitutes.

This prohibitive cost factor led this paper to focuses on the utilization of abundant granular sulphur as an extender for the more expensive bituminous material. In this study, sulphur-extended binders were prepared by using a 50/70 grade bitumen and by increasing the amounts of granular sulphur as an extension up to a maximum $50 \%$ by weight. The samples were then exposed to short and long-term aging by performing the Rolling Thin Film Oven and Pressure Aging Vessel tests. Aged and virgin samples were then further tested using analytical, rheological, and morphological testing methods. The promising results demonstrate that the sulphur-extended binder not only increases the performance of the neat bitumen, but can also lower overall costs.
\end{abstract}

Keywords: Sulphur, bitumen, extension, aging 


\section{Introduction}

The durability of flexible pavements to both traffic loads and environmental conditions is primarily dependent on the bitumen used and its chemical composition. In the past, pavements made of neat bitumen met the required specifications and performed satisfactorily under the axle loads and conditions of those years. However, the substantial increases in traffic loads, traffic volume, and increased tire pressures have negatively affected the performance of the neat bitumen, and have also resulted in additional detrimental distresses in straight bitumen pavements. These distresses include: rutting, shoving, stripping, and fatigue cracks, which are caused by not only traffic loads but also weather conditions (Taha et al.1998). Therefore, stakeholders have been trying to enhance the properties of neat bitumen by finding a more convenient, practical and cost effective way, one that is economical, environment-friendly, and - particularly - compatible with current international specifications.

Since the 1970s, a great interest has been raised and numerous attempts have been made to improve the properties of bitumen via various modifications (Elseifi et al. 2003). One of these modifications is devoted towards modifying the bitumen by adding sulphur.

A non-polymer modifier, it is hoped that the blending of sulphur with bitumen will result in the enhancement of its mechanical and rheological properties. It has been determined that sulphur can be used as an extender by using it as a partial or complete replacement for both straight and modified bitumen (Asphalt Institute 2007). Among its positives is that of cost, for the price of sulphur is approximately five to six times less expensive than conventional bitumen (Asphalt Institute 2007). In addition to its lower cost, sulphur is also substantially and readily available as it can be sourced from both natural sources and also from blast furnaces. Thermal plants also offer a high potential as a sulphur source. Therefore, instead of discarding this sulphur, researchers have been looking for ways that it can be utilized in road pavements (Deniz 2009). At the moment, however, the current lack of detailed assessments is restricting the use of sulphur in the constructions of pavements, both in Turkey and in the rest of the world. The goal of this study is to investigate the potential applicability of sulphur as an extender in neat bitumen by testing its responses to aging, rheology, morphology, sustainability, etc. 


\section{Earlier Studies}

Previous studies revealed the stiffening effect of sulphur on asphalt (Kennedy and Haas 1980; Miller and Crawford 1981). According to their obtained results, this stiffness was generally higher while permanent shear strain or rutting were lower for those asphalt mixtures using sulphur than they were for those mixtures that had not been extended with sulphur (Kandhal 1982; Akili 1983; Bayomy and Khedr 1987; McBee et al. 1980). In addition to its comparable pavement performance, it has been suggested that a sulphur-extended binder (SEB) would lead to decreased costs for hot-mix asphalt (HMA) production as it would decrease the needs for other more expensive bituminous binders, while also resulting in remarkable fuel savings due to both lower mixing and compaction temperature ranges (Asphalt Institute 2007).

In an environmental-focused study, Filippis et al. (1998) conducted research on SEB designed to reveal the reaction kinetics of the $\mathrm{H}_{2} \mathrm{~S}$ evolution. They concluded that when heating SEB mixtures, special attention should be taken in order to avoid pollution and safety problems in terms of $\mathrm{H}_{2} \mathrm{~S}$ emissions at temperatures higher than $140^{\circ} \mathrm{C}$.

Chen and Huang (2007) studied the role of sulphur on the fundamental characterization of polymermodified asphalt (PMA) in terms of viscosity, microscopy and rheology. According to their findings, following the addition of sulphur, the PMA was seen to have smaller bitumen domains and a fairly homogeneous dispersion of the bitumen in the styrene-butadiene-styrene (SBS) matrix. The addition of sulphur formed an excellent elastic system and considerably increased the rheological properties.

Martínez-Estrada et al. (2010) investigated the effects of sulphur on the morphology and rheological properties of styrene-butadiene (SB)- and SBS-modified bitumen. They concluded that sulphur considerably increased the compatibility between polymer and bitumen by cross-linking the polymer chains. They further reported that the addition of small amounts of sulphur to SB-modified bitumen facilitated the formation of an elastomeric network resembling the ones found in SBS-modified bitumen, thus effectively contributing to asphalt reinforcement. 


\section{Experimental Program}

The materials used and the processes applied in this study are given below.

\subsection{Materials}

A 50/70 pen bitumen, one of the most common used in Turkey, was sourced from TUPRAS, Turkey's largest petrochemical company. Sulphur, available in a 2 to $3 \mathrm{~mm}$ granular shape, was used as an extender and was sourced from the EGE Development Chemistry Cooperation, Izmir, Turkey.

In preparing the SEBs, about $500 \mathrm{~g}$ of the neat $50 / 70$ grade bitumen was heated in a metal container until fluid. At $140^{\circ} \mathrm{C}$ it was separately extended with $10,20,30,40$ and 50 percent of the granular sulphur (GS) based on weight. The mixing of the bitumen and GS was performed using a digital high shear mixer (EUROSTAR made by IKA, Staufen, Germany), and rotated at 1000rpm for 60 minutes. During each blending process the sulphur extension was given special attention and the blending was performed per relevant protocols in order to: minimize the bitumen degradation, obtain a homogenous blend, allow chemical bonds to be created, and prevent both possible crystallization and the emissions of poisonous $\mathrm{SO}_{2}$ and $\mathrm{H}_{2} \mathrm{~S}$ gases. Subsequent to cooling, each $\mathrm{SEB}$ sample was covered with plastic bags and then stored in a closed darkened area to avoid oxygen and ultraviolet light.

A Brookfield Rotational Viscometer DV III Ultra (Brookfield Engineering Laboratories, Middleboro, Massachusetts) was used to measure the viscosity at the constant speed of the spindle (20rpm) and at 105,135 and $165^{\circ} \mathrm{C}$ as per guidelines prescribed in ASTM standard D4402 (ASTM 2015a). The obtained viscosity grades were utilized to appoint equiviscous temperature ranges for determining convenient mixing and compaction temperatures.

The two most widely used tests were applied to simulate aging for samples: the Rolling Thin Film Oven Test (RTFOT) and the Pressure Aging Vessel (PAV). For short-term aging, the binders were exposed to RTFOT ( 85 minutes at $163^{\circ} \mathrm{C}$ ) as described in ASTM standard D2872 (ASTM 2012).

Then the long-term aging process was performed with PAV to simulate bitumen in-service. This was carried out by aging the pre-aged samples (via RTFOT) for 20 hours at $100^{\circ} \mathrm{C}$ under $2.1 \mathrm{MPa}$ of air as detailed in the ASTM standard D6521 (ASTM 2013). 
To measure the dynamic rheology of the un-aged, short and long-term aged samples a dynamical mechanical analysis was performed at a frequency of $1.59 \mathrm{~Hz}$ and at four different temperatures $(25,30$, 40, and $50^{\circ} \mathrm{C}$ ) using a stress-controlled rheometer with parallel plate geometry. During the study, a Malvern Bohlin DSR II Air Bearing (Malvern Instruments, Malvern, U.K.) was used to measure the rheological parameters as detailed in ASTM standard D7175 (ASTM 2015b).

The morphology of the samples was investigated using a high quality scanning electron microscope (SEM, JEOL JSM-7001 F, Joel, Peabody, Massachusetts). Before the operation, three samples representing each of the same binder's different phases (un-aged, RTFOT-aged, and PAV-aged) were prepared by using very small amounts of the sample. Nonconductive samples tend to charge when scanned by the electron beam, and especially in secondary electron imaging mode, causing scanning errors and other image artifacts. In order to prevent any faults and artifacts, the SEBs were coated with an ultra-thin coating of gold and then viewed under a microscope at a magnification of $1000 \mathrm{X}$.

\section{Analysis of Results}

\subsection{Viscosity Behavior}

As shown in Table 1, at the un-aged stage, regardless of GS proportion all SEBs had lower rotational viscosity values than the base $50 / 70$ pen bitumen had at 105,135 , and $165^{\circ} \mathrm{C}$.

The introduction of low amounts sulphur (10 and/or 20\%GS) lowered the viscosity and hardness at each of the three temperatures of both the un-aged and short-term aged 50/70 pen bitumen. Hence, in terms of stiffness, a relatively softer binder (B50/70+10\%GS or B50/70+20\%GS) was created. The change towards a more viscous behavior confirms the assumption that low amount of sulphur generates viscous networks in bitumen matrix.

At $105^{\circ} \mathrm{C}$ none of the SEBs appeared to have similar viscosities to that of the original $50 / 70$ pen bitumen. However, there were minimal viscosity variations between the SEBs containing 10 and 20\% proportion of GS as noted. Furthermore, the trio of SEBs with $30 \%, 40 \%$, and $50 \% \mathrm{GS}$ had close viscosity values of: 1975, 2067, and 1913c-P respectively. 
At $135^{\circ} \mathrm{C}$ the $10 \% \mathrm{GS}$ extension reduced the viscosity of the original $\mathrm{B} 50 / 70$ bitumen sample by nearly half (46.00\%). The SEBs containing further amounts of GS had close viscosity grades, while the SEBs containing $20 \%$ and $50 \% \mathrm{GS}$ had the same viscosity measurements: $213 \mathrm{c}-\mathrm{P}$. In accordance with the Strategic Highway Research Program (SHRP) requirements, the viscosities of all SEBs at $135^{\circ} \mathrm{C}$ met the required ranges ( 80 to $3000 \mathrm{c}-\mathrm{P})$.

At $165^{\circ} \mathrm{C}$ all SEBs, other than that of $10 \% \mathrm{GS}$ had nearly the same viscosity values, varying between 63-81c-P with values still lower than that of the base B50/70: 150c-P.

In order to understand how aging affects the permanent viscosity grades of the derivatives of $\mathrm{B} 50 / 70$, the test was again performed on all short-term aged residues at 105,135 and $165^{\circ} \mathrm{C}$. Unsurprisingly, various permanent viscosity losses occurred, depending on the amounts of bitumen and sulphur. Due to its relatively hard bitumen (B50/70) - having been composed of 50\%GS and having been short-term aged via RTFOT - the viscosity measurement of B50/70+50\%GS residue could not be performed at $105^{\circ} \mathrm{C}$. The value was unreadable since it exceeded the testing machine's maximum available viscosity grade, $12500 \mathrm{c}-\mathrm{P}$. The results showed that at $105^{\circ} \mathrm{C}$ a maximum permanent viscosity loss was observed for the B50/70+50\%GS residue and the minimum permanent viscosity loss observed for the short-term aged base B50/70 bitumen residue (49.68\%) and then for B50/70+20\%GS residue (57.06\%) respectively. The other permanent viscosity values at 135 and $165^{\circ} \mathrm{C}$ are included in the rheological aging index to give a perspective to the hardening effects on the sample behavior.

In order to determine the optimum laboratory mixing and compaction temperatures, equiviscous temperature ranges were also explored. This is a method that has been used by asphalt mix design procedures for quite a while (Asphalt Institute 2010). These equiviscous ranges used in the Marshall Mix design and currently in the Superpave mix design were originally designed for neat or unmodified bituminous binders but not for other specific binders such as these new SEBs. Nevertheless, it is expected that this will also work well with SEBs.

The viscosities obtained at two different temperatures $\left(135\right.$ and $\left.165^{\circ} \mathrm{C}\right)$ were first plotted on the $\log$-log viscosity vs. log temperature graph. In this graph, a linear relationship between viscosity $(\log -\log$ scale) and temperature (log scale) was established by having only two data points. Then using 150 and 


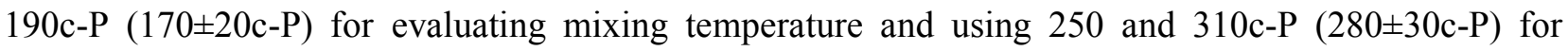
evaluating compaction temperature, the mixing and compaction temperatures were assigned for neat 50/70 pen bitumen and each SEB sample. The results are given in Table 2.

Since 50/70 pen bitumen itself is already a relatively hard binder, the hot mix asphalt made of B50/70 is unquestionably expected to have a high temperature range for both mixing and compaction. Table 2 shows the equiviscous temperatures, its mixing range varies from 157.62 to $163.55^{\circ} \mathrm{C}$ and its compaction range, which varies from 146.01 to $151.01^{\circ} \mathrm{C}$ respectively. The attainment of these high mixing temperatures will both require huge fuel consumptions and will inevitably result in a large amount of hazardous gas emissions. Moreover, at these high mixing and compaction temperatures, B50/70 pen bitumen will be exposed to excessive aging in both hot mix plant and field conditions, making the retention of its initial viscosity grade and stiffness impossible. On the other hand, all derivative SEBs of the B50/70 grade bitumen, including even the B50/70+50\%GS, have a lower mixing and compaction temperature range as shown in Table 2. However, the magnitude of decrease in both mixing and compaction temperature does not seem to vary in a regular fashion with varying amount of sulphur. The proposed approach indicates that the mixing temperature will be about $12^{\circ} \mathrm{C}$ lower when the $10 \%$ sulphuric extension is taken into account. For compaction temperature, a reduction of about $11^{\circ} \mathrm{C}$ is observed. Among the all SEBs, the highest decline in both mixing and compaction temperature is seen for $\mathrm{B} 50 / 70-20 \% \mathrm{GS}$ (about 18 and $16^{\circ} \mathrm{C}$ respectively). Under these circumstances and corresponding to their viscosity grades, all derivative SEBs of B50/70 show promise in utilizations for "warm-asphalt" production.

\subsection{Rutting Resistance}

Rutting is a typical permanent deformation that reduces both driving comfort and safety. Asphalt concrete pavement has a high tendency to rut shortly after it is laid. Repeated traffic loads trigger the consolidation of the pavement structure after construction thus resulting in rutting, predominantly so in traffic lanes especially used by heavy-loaded vehicles. The rutting potential of pavement is influenced by several parameters, including: compaction quality, mix design, aggregate angularity and texture. The idea that a bituminous binder plays a considerable role in this aspect is a new concept. Since bitumen 
becomes more fluid with rising temperatures, rutting commonly occurs at high service temperatures (Bahia and Anderson 1995; Roberts et al. 1996; John and Micheal 2004).

SHRP developed a specification property of $\mathrm{G}^{*} / \sin \delta$ to evaluate a binder's rutting performance (Maccarrone et al. 1995). (Here the complex modulus $G^{*}$ is used as a measurement of the total resistance of a material to deformation under cyclic loading conditions and $\delta$, the phase angle as an indicator of the relative amount of recoverable and non-recoverable deformation).

The parameter indicating rutting resistance in the Superpave specifications has been calculated for each SEB, with the values displayed in Figure 1 . With the exception of $40^{\circ} \mathrm{C}, 10 \% \mathrm{GS}$ extended SEB is shown to have a lower rutting resistance value than neat 50/70 grade bitumen. Previous studies have demonstrated that following its addition to neat bitumen, a certain amount of the sulphur reacted with the bitumen, leading to both physical and chemical variations over time (Kennepohl and Miller 1978; Rennie 1979). In this sense, not only does this SEB decrease the stiffness but also decreases the viscosity. This most probably stems from ongoing reactions between sulphur particles and bitumen compounds. In this work, regardless of temperature, further GS replacement did not only cause the rutting resistance to exceed the value of neat bitumen, but also it decreased the stiffness of the neat bitumen. This result is also in agreement with previously reported viscosity results, suggesting that an addition of GS up to $20 \%$ resulted in a less stiff binder. Although the $30 \% \mathrm{GS}$ extension yields a significant increase in rutting deformation at increased temperatures, the effect is not as marked as that seen for a temperature of $25^{\circ} \mathrm{C}$. However, for each rise in temperature, a remarkable increase in the parameter of $\mathrm{G}^{*} / \sin \delta$ takes place when the amount of GS is $40 \%$, reaching a value evidently higher than that found for neat bitumen. This result suggests that it is not the chemical reactions, but rather the appreciable sulphur-bitumen bonds that developed during the mixing process that lead to a remarkable rutting stiffness at each test temperature. Figure 1 also shows that a 50\% sulphur utilization resulted in a binder having nearly identical viscoelastic behavior as that containing no GS (neat bitumen). Hence, the observed results demonstrate that the inclusion of $40 \% \mathrm{GS}$ into $50 / 70$ pen bitumen evokes a significant amount of increase in elasticity, thus emphasizing the occurrence of a considerable shift of rheological behavior from visco-like to a more elastic-like body. 


\subsection{Deformation Resistance}

The storage and loss modulus in bituminous binders are an implied measurement of stored energy, indicating that the elastic portion and the energy that is dissipated as heat indicates the viscous portion respectively (Meyers and Chawla 1999). As a viscoelastic material, bituminous binder is expected to have a large storage modulus value $\left(G^{\prime}\right)$, especially at high temperatures for deformation endurance due to fact that $G^{\prime}$ represents the binder elasticity (Lu and Isacsson 1997). However, since it displays a more brittle behavior at low temperatures, bitumen must have a low elasticity and a high viscosity for energy dissipation to prevent cracking (Kumar et al. 2010). The loss modulus $\left(G^{\prime \prime}\right)$ and storage modulus $\left(G^{\prime}\right)$ of SEB samples at different temperatures are given in Figure 2 and Figure 3 respectively.

It is clear that as the temperature increases, the loss modulus of each SEB decreases as shown in Figure 2. Consistent with the trend observed in the viscosity results, the values of $G^{\prime \prime}$ for extended binders with 10 and $20 \% \mathrm{GS}$ are lower than that of neat bitumen and this gap is more particularly distinctive in the case of $20 \% \mathrm{GS}$ utilization. A further increase in sulphur content is seen to cause an increase in the value and then the viscous behavior shown by SEB with $30 \% \mathrm{GS}$, becoming nearly similar to that of neat B50/70 grade bitumen except at low temperatures. Regardless of temperature, the 40\%GS SEB holds the highest loss modulus values, which indicates that this percentage of sulphur provides the utmost viscous effect. Contrary to expectations, a further increase in GS amount did not further increase the rutting deformation; a decline in $G^{\prime \prime}$ is obvious in case of the $50 \% \mathrm{GS}$ extension, but the value is still comparable to that of the $50 / 70$ pen bitumen.

Under the same experimental conditions, the graph line of the linear evolution of the storage modulus with all temperatures for neat bitumen is significantly higher than for the $10 \%$ and $20 \% \mathrm{GS}$ extended bitumen as shown in Figure 3. Temperatures up to $40^{\circ} \mathrm{C}$ have no influence on the values of B50/70 bitumen extended with $10 \% \mathrm{GS}$, and the slope is almost equal to 0 . Among all the SEBs, only that with $40 \% \mathrm{GS}$ displayed an increase in $G^{\prime}$ in the $1.59 \mathrm{~Hz}$ frequency relative to neat bitumen. This underlines the fact that higher increases in the storage modulus (which provides information on the elastic response of the binder shown by the $40 \% \mathrm{GS}$ extended bitumen) may not yield a better 
performance of the binder especially at low temperatures. Therefore, the results based on the laboratory tests show that the SEBs with $10 \%$ and $20 \%$ GS will be more durable in terms of low temperature cracking. However, it should be noted that the results in the field may display some variations.

\subsection{Aging Effect}

It is clear that due to aging the ultimate behavior of bitumen will almost totally differ from its original configuration. Bitumen aging is usually evaluated by calculating an aging indicator to the ratio of one parameter of the aged bitumen to that of the original bitumen. As a simple general approach, the higher the aging indicator, the higher the degree of bitumen hardening (Lu and Isacsson 1998). Rheological, mechanical or chemical indicators are just some of the many indicators available that allow pavement engineers to evaluate the influence of aging on bitumen hardening. Rheological aging indicators include retained penetration, changes in softening point temperatures, mass changes, viscosity ratios, rheological index and tensile/creep strength. For this study, viscosity ratio and rheological index were measured to reveal the aging effects on the samples.

The viscosity ratios and the rotational viscosity values for each specimen were previously presented in Table 1. The results confirm a consistent increase in viscosity by short-term aging. As with results observed at the un-aged stage, the increasing sulphur content first decreased and then increased the viscosity grade. As seen in Table 1, the retained viscosity grades of each SEB, excepting that of $50 \% \mathrm{GS}$, seem to be lower than that of the neat bitumen at both 135 and $165^{\circ} \mathrm{C}$. Viscosity ratios for each of the SEBs, however, appear greater than that of neat bitumen, showing that sulphur extension makes 50/70 grade bitumen more susceptible to aging. This may be due to further melting of GS at higher temperatures during the RTFOT process, which results in a vulnerable binder in terms of aging.

The rheological index obtained from the ratio of the complex modulus $\left(G^{*}\right)$ of aged (via RTFOT and PAV) binder to the complex modulus of un-aged binder is the second parameter assigned. The values of the rheological index at $1.59 \mathrm{~Hz}$ frequency and at four different temperatures for the neat B50/70 grade bitumen and SEBs are listed in Table 3 and Table 4. Table 3 shows the rheological index presenting the correlation between un-aged and short-term aged samples, whereas Table 4 shows the rheological index presenting the correlation between un-aged and long-term aged samples. 
It can be deduced from Table 3 that the aging index seems to be greater than 1 at each temperature $\left(25\right.$ to $\left.50^{\circ} \mathrm{C}\right)$ and at $1.59 \mathrm{~Hz}$ for the all extended binders, except the one containing $30 \% \mathrm{GS}$, which points to the hardening of these SEBs during short-term aging (via RTFOT). This increase in the rheological index is due to oxidation, that is, the transformation of light particles such as aromatics into resins and these into asphaltenes, which develops a considerable bitumen hardening (Pérez-Lepe et al. 2003). In addition to this oxidation phenomenon, ongoing bonds between sulphur particles and bitumen compounds during aging are believed to contribute significantly to SEB hardening. However, for neat $50 / 70$ grade bitumen this value is lower than 1 only at a low temperature $\left(25^{\circ} \mathrm{C}\right)$ and for the SEB with $30 \% \mathrm{GS}$ it is lower at both low and moderate temperatures $\left(25\right.$ and $\left.40^{\circ} \mathrm{C}\right)$. This worsening influence of short-term aging on the $30 \%$ GS SEB can be attributed to the breakage of initially formed sulphur networks during RTFOT aging.

As seen in Table 4, as the temperature is increased to $50^{\circ} \mathrm{C}$, the general rise in the rheological index reveals that the influence of long-term aging has become more distinctive.

The values of both rheological indexes show that the aging index indicator for extended binders is typically higher than 1 and rarely lower than 1 . This variation is fundamentally dependent on several parameters, such as the neat bitumen type, sulphur amounts, temperatures, frequency and aging.

Figures 4(a) through (c) demonstrate the variations in the complex modulus in the temperature ranges from 25 to $50^{\circ} \mathrm{C}$ and at the frequency of $1.59 \mathrm{~Hz}$ before aging and after both short and long-term aging. Regardless of the aging phenomenon and sample types, the complex modulus appears to decrease as the temperature increases; this differentiation is more pronounced while the temperature is converging to $50^{\circ} \mathrm{C}$. Figure $4(\mathrm{a})$ shows that before aging, the $40 \% \mathrm{GS}$ extended bitumen holds the highest complex modulus value at each temperature compared both with other SEBs and neat bitumen.

After short-term aging, the $G^{*}$ values of $10 \%$ and $30 \%$ GS SEBs appeared to be less sensitive to any changes in temperature when compared against the other SEBs. Figure 4(b) also illustrates that these two samples seem to have comparable viscoelastic responses both with each other and with the neat bitumen, even though these binders had different chemical structure owing to different levels of GS. 
According to Figure 4(c), as expected, long-term aging ensured a further increase in the complex modulus over the temperature range due to relatively large stiffening by prolonged aging. The promising improvement in the complex modulus of the PAV residual binder is most probably consistent with two parts of the scenario: the further loss of the lighter compounds of the bitumen and the further dissolution and dispersion of sulphur particles in bitumen phase through pressure aging (Huang 2008). What is more noticeable is that, as seen in Figure 4(c), long-term aging showed a flattening out of the plateau effect for the complex modulus. In addition to the increased complex modulus of the $50 \% \mathrm{GS}$ SEB, a corresponding plateau also very clearly appeared. This is a desirable phenomenon and an indication of improved elasticity possibly causing an enhanced resistance to deformation of an asphaltic concrete pavement.

\subsection{Morphological Behavior}

The microscopic compatibility between sulphur particles and bitumen compounds was investigated to reveal the morphological properties of SEBs before and after both short and long-term aging ( $\mathrm{o}, \mathrm{r}$, and $\mathrm{p}$ represent original age, short-term aging, and long-term aging, respectively). For the 10\%GS included sample, sulphur particles were finely dissolved in a continuous and dominant bitumen phase, as shown in Figure 5(b)-o. This preliminary analysis hints as to why its viscosity grade and rutting resistance decreased so strongly. Compared with the un-aged stage, as dissolved sulphur particles increased in size, they started to be become visible after the RTFOT aging, as shown in Figure 5(b)-r. Even though a bigger cluster of particle is visible, which is an indicator of phase separation of binder and sulphur as presented in Figure 5(b)-p, the influence of long-term aging generally led the sulphur particles to decline in size, with their outlines becoming relatively homogeneous, thus underlining the further dissolution of GS and the fact that the GS and bitumen have further improved in compatibility over time.

Inspection of the micrograph Figure 5(c)-o for the 20\%GS SEB reveals that both dissolved fine particles and coarse particles of sulphur are present in the bituminous phase. As seen on the SEM micrograph, their radii (ranging between 5 and 10 $\mu \mathrm{m}$ ) are, however, negligible as it is evident that these 
large aggregates of sulphur particles are mostly localized on the surface of the bitumen. The short-term aging effect is exhibited in Figure 5(c)-r. After exposing this SEB to RTFOT, the light dots representing the swollen sulphur particles clearly dissolved. As shown in Figure 5(c)-p, once the same SEB is subjected to long-term aging, the smaller proportions of the sulphur usually segregated into small regions on the bitumen phase.

The morphological nature of the sulphur-rich phase and bitumen-rich phases for the $30 \% \mathrm{GS}$ SEB before and after aging are illustrated in Figures 5(d)-o-r-p. When secured in the continuous matrix formed by the bitumen, the sulphur exhibited a biphasic morphology. The small, almost invisible light spots are indications of the dissolved sulphur and the coarse irregular shaped sulphur particles indicate the dispersed sulphur. After short-term aging the coarse particles reduced considerably or disappeared altogether, thus causing an increase in the dissolved sulphur proportion when compared to the un-aged stage of the same SEB, leading to a very homogenous matrix. Therefore, the major effect of short-term aging on the morphology of the SEB is its effect on the homogeneous distribution of sulphur in the bitumen matrix. This further improvement in the compatibility between sulphur and bitumen is most probably caused by the further aging due to the severe degradation of GS. After PAV aging, the large sulphur particles seemed to have appeared on the upper surface of the bitumen phase.

The morphological views for un-aged, short- and long-term aged stage of the $40 \%$ GS SEB are given in Figures 5(e)-o-r-p. The presence of dominant coarse sulphur particles reveals the rough surface of the un-aged SEB. This most probably stems from an excessive amount of sulphur, one which surpasses the optimum extension capacity of the neat bitumen. The sulphur particles had a visual tendency to create fishbone-looking crystalline structures after the SEB was subjected to RTFOT. Further aging did not paint a different picture.

Increasing the sulphur content to $50 \%$ yielded different pictures in terms of morphology. The views belonging to un-aged, short- and long-term aged sample are shown in Figures 5(f)-o-r-p. In the initial stage, sulphur displayed a multiphasic morphology. The remarkable amount of sulphur that had dissolved in the bitumen matrix developed a colloidal form, while the rest dispersed heterogeneously relative to size. Among the all SEBs with various GS amounts, this is the first example of large (greater 
than $10 \mu \mathrm{m}$ ) sulphur particles noted before the aging process. After short-term aging, the morphology changed from one with coarse sulphur particles to a crystalline structure. This verifies that the compatibility between the GS and bitumen increases over time. The image also clarifies that this crystalline structure, one which resembles cream, is dominating the upper surface of the bitumen. However, as a consequence of the prolonged aging time in PAV, the network between sulphur aggregations on the surface was evidently destroyed and the size of the crystalline structure was seen to decline.

Finally, the spectrum processing analysis was carried out to reveal how much each sample included carbon (C) and sulphur (S) elements in terms of both weight and atomic percentages. The measured values given in Table 5 demonstrate the impact of aging on the chemical composition of the each SEB before and after aging (both RTFOT and PAV aging). It is noteworthy to point that both physical and chemical bonds developed between sulphur particles and bitumen compounds play major roles on the chemical structure of the SEBs. As compared to their RTFOT-aged stages, the SEBs with 10, 20, and 40\%GS were observed to have lower sulphur content upon PAV aging. The most probable reason for this decline was due to breakdown of the initial bonds after exposure to prolonged pressure aging. As a consequence, unrestricted sulphur particles became prone to evaporation. This decrease in sulphur amounts of these binders confirms a consistency with the trends observed in their morphological changes. Compared with their RTFOT aging micrographs (5(b)-r, 5(c)-r, and 5(e)-r), a significant amount of light colored sulphur particles apparently decreased after PAV aging, as shown in Figure 5(b)-p, 5(c)-p, and 5(e)-p.

\section{Conclusions}

The test results obtained in this study led to the following conclusions:

- Regardless of temperature and amount of granular sulphur, all sulphur-extended binders have a lower viscosity grade than that of neat $50 / 70$ bitumen. This demonstrates that the SEBs can achieve more resistance to cracking, especially at low temperatures.

- Consistent with trends observed in viscosity grades, a considerable decline in both mixing and compaction temperatures for all SEBs is obvious. This reinforces the assumption that fuel 
consumption will decrease considerably, thus leading to a reduced amount of hazardous gas emissions during hot mix asphalt production.

- Along with the viscosity ratio, the aging index was also measured so that the rheological parameters of the aged bitumen could be compared to that of the un-aged bitumen so as to reveal the effects of both short and long-term aging. The rheological index appeared to be greater than 1 in all test temperatures $\left(25\right.$ to $\left.50^{\circ} \mathrm{C}\right)$ at $1.59 \mathrm{~Hz}$ frequency for all SEBs excepting the $30 \% \mathrm{GS}$ SEB. This allows pavement engineers to understand the hardening of these sulphur-extended binders during RTFOT aging. After long-term aging via PAV the values generally rose significantly due to the oxidative pressure aging effect.

- Among all the SEBs, the $40 \% \mathrm{GS}$ sample displayed better resistance to rutting deformation. This case can be promising in cases of very high temperature areas with heavy traffic volume.

- Morphology results demonstrate that a good compatibility of sulphur in bitumen matrix is present up to a $40 \% \mathrm{GS}$ extension.

To sum up, the purpose of this paper has been to conduct an in-depth and integrated study relative to the potential sulphur utilization in bituminous binder. Although both the obtained analytical and morphological test results and rheological characteristics demonstrate encouraging potentials of sulphurextended-binders, it should be noted that the findings are at the preliminary stage and that hence there is more to do on this subject, especially in terms of the topic's environmental aspects.

\section{References}

Akili, W. 1983. On the use of sulphur in sand-asphalt applications. Proceedings of the Association of Asphalt Paving Technologists, Vol. 52(83): 561-584.

Asphalt Institute. 2007. State-of-knowledge on the use of sulfur-extended asphalt (SEA). Asphalt Institute Executive Offices and Research Center, Lexington, KY.

Asphalt Institute. 2010. Asphalt institute technical bulletin: Laboratory mixing and compaction temperatures. Asphalt Institute Executive Offices and Research Center, Lexington, KY. 
ASTM. 2012. Standard test method for effect of heat and air on a moving film of asphalt (rolling thin-film oven test). ASTM standard D2872-12e1. ASTM International, West Conshohocken, PA. doi: 10.1520/D2872-12E01.

ASTM. 2013. Standard practice for accelerated aging of asphalt binder using a pressurized aging vessel (PAV). ASTM standard D6521-13. ASTM International, West Conshohocken, PA. doi: 10.1520/D6521.

ASTM. 2015a. Standard test method for viscosity determination of asphalt at elevated temperatures using a rotational viscometer. ASTM standard D4402/D4402M-15. ASTM International, West Conshohocken, PA. doi: 10.1520/D4402_D4402M-15.

ASTM. 2015b. Standard test method for determining the rheological properties of asphalt binder using a dynamic shear rheometer. ASTM standard D7175-15. ASTM International, West Conshohocken, PA. doi: 10.1520/D7175-15.

Bahia, H.U., and Anderson, D.A. 1995. The development of the bending beam rheometer; basics and critical evaluation of the rheometer. Physical properties of asphalt cement binders. ASTM International, pp. 28-50. doi: 10.1520/STP18187S.

Bayomy, F.M., and Khedr, S.A. 1987. Sulfur as a partial replacement for asphalt in pavement. $66^{\text {th }}$ Annual Meeting of the Transportation Board, Transportation Research Board, Washington, DC, pp. 150-160.

Chen, J.S., and Huang, C.C. 2007. Fundamental characterization of SBS-modified asphalt mixed with sulfur. Journal of Applied Polymer Science, 103(5): 2817-2825. doi:10.1002/app.24621.

Deniz, M.T. 2009. The usage of granular sulphur with bitumen as a binder and its effect on the permanent deformations. Ph.D. Thesis, Department of Civil Engineering, Istanbul Technical University, Istanbul, TR.

Elseifi, M., Flintsch, G., and Al-Qadi, I. 2003. Quantitative effect of elastomeric modification on binder performance at intermediate and high temperatures. Journal of Materials in Civil Engineering, 15:1(32): 32-40. doi: 10.1061/(ASCE)0899-1561(2003)15:1(32). 
Filippis, P.D., Giavarini, C., and Santarelli, M.L. 1998. Sulphur-extended asphalt: reaction kinetics of $\mathrm{H}_{2} \mathrm{~S}$ evolution. Fuel, 77(5): 459-463. doi:10.1016/S0016-2361(98)80037-9.

Huang, S. 2008. Rubber concentrations on rheology of aged asphalt binders. Journal of Materials in Civil Engineering, 20(3): 221-229. doi:10.1061/(ASCE)0899-1561(2008)20:3(221).

John, P.Z., and Michael, E.P. 2004. Evaluation of performance graded asphalt binder equipment and testing protocol. Asphalt Technology Program, Department of Civil and Environmental Engineering, West Virginia University, Morgantown, West Virginia.

Kandhal, P.S. 1982. Evaluation of sulphur extended asphalt binders in bituminous paving mixtures. Proceedings of the Association of Asphalt Paving Technologists, 51(82): 189-221.

Kennedy, T.W., and Haas, R. 1980. Sulphur-asphalt technology: A review of progress. Transportation Research Record 741, Transportation Research Board, Washington, DC, pp. 150-160.

Kennepohl, G.J.A., and Miller, L.J. 1978. Sulfur asphalt binder technology for pavements. Chapter 7, New uses of sulfur-II, Vol. 165, American Chemical Society, Washington, DC, pp. 113134.

Kumar, P., Mehndiratta, H., and Singh, K. 2010. Comparative study of rheological behavior of modified binders for high-temperature areas. Journal of Materials in Civil Engineering, 22(10): 978-984. doi:10.1061/(ASCE)MT.1943-5533.0000099.

Lu, X., and Isacsson, U. 1997. Rheological characterization of styrene-butadiene-styrene copolymer modified bitumens. Construction and Building Materials, 11(1): 23-32. doi:10.1016/S09500618(96)00033-5.

Lu, X., and Isacsson, U. 1998. Chemical and rheological evaluation of ageing properties of SBS polymer modified bitumen. Fuel, 77(9): 961-972. doi: 10.1016/S0016-2361(97)00283-4.

Maccarrone, S., Holleran, G., and Gnanseelan, G.P. 1995. Properties of polymer modified binders and relationship to mix and pavement performance. Journal of the Association of Asphalt Paving Technologists, 64(95): 209-240. 
Martínez-Estrada, A., Chávez-Castellanos, A.E., Herrera-Alonso, M., and Herrera-Nájera, R. 2010. Comparative study of the effect of sulfur on the morphology and rheological properties of SB- and SBS-modified asphalt. Journal of Applied Polymer Science, 115(6): 3409-3422. doi:10.1002/app.31407.

McBee, W.C., Sullivan, T.A., and Saylak, D. 1980. An overview of sulfur-extended asphalt usage. In Asphalt Pavement Construction: New Materials and Techniques. ASTM International, pp. 39-63. doi:10.1520/STP38364S.

Meyers, M.A., and Chawla, K.K. 1999. Mechanical behavior of materials. Prentice-Hall, Upper Saddle River, NJ, pp. 98-103.

Miller, L.J., and Crawford, W.W. 1981. A technical review of sulphur-asphalt technology. Proceedings of the $26^{\text {th }}$ Annual Conference of the Canadian Technical Asphalt Association, Montreal, PQ Canada, pp. 386-417.

Pérez-Lepe A., Martínez-Boza F.J., Gallegos C., González O., Muñoz, M.E., and Santamaría, A. 2003. Influence of the processing conditions on the rheological behaviour of polymermodified bitumen. Fuel, 82(11): 1339-1348. doi:10.1016/S0016-2361(03)00065-6.

Rennie, W.J. 1979. Sulphur asphalts. New uses for sulphur technology, Sulphur Development Institute of Canada, Calgary, AB, Canada, pp. 1-13.

Roberts, F.L., Kandhal, P.S., Brown, E. R., Lee, D., and Kennedy, T.W. 1996. Hot mix asphalt materials, mixture design and construction. $2^{\text {nd }}$ Edition. NAPA Research and Education Foundation, Lanham, Maryland, USA.

Taha, R., Ali, G., and Delwar, M. 1998. Evaluation of coke dust-modified asphalt using Superpave. Journal of Materials in Civil Engineering, 10(3): 174-179. doi: 10.1061/(ASCE)0899-1561(1998)10:3(174). 


\section{Figure Captions}

Figure 1. $\mathrm{G}^{*} / \mathrm{sin} \delta$ measured at $1.59 \mathrm{~Hz}(10 \mathrm{rad} / \mathrm{s})$ as a function of temperature for $\mathrm{B} 50 / 70$ extended with various GS amount before aging.

Figure 2. Loss modulus measured $\left(G^{\prime \prime}\right)$ at $1.59 \mathrm{~Hz}(10 \mathrm{rad} / \mathrm{s})$ as a function of temperature for SEB samples before aging.

Figure 3. Storage modulus measured $\left(G^{\prime}\right)$ at $1.59 \mathrm{~Hz}(10 \mathrm{rad} / \mathrm{s})$ as a function of temperature for SEB samples before aging.

Figure 4. (a), (b), (c) Complex modulus $\left(G^{*}\right)$ at $1.59 \mathrm{~Hz}(10 \mathrm{rad} / \mathrm{s})$ as a function of temperature for B50/70 bitumen and its extensive binders before aging, after short-term aging, and after long-term aging respectively.

Figure 5. Morphology development of each SEB made of B50/70 and GS before aging and after RTFOT and PAV aging (scanning electron microscopy) at magnification of X1000. (a) neat B50/70. (b) B50/70+10\%GS. (c) B50/70+20\%GS. (d) B50/70+30\%GS. (e) B50/70+40\%GS. (f) B50/70+50\%GS. o, $\mathrm{r}$ and p presenting picture of original, RTFTO-aged and PAV-aged stage respectively. 


\section{List of Tables}

Table 1: Viscosity measurements.

Table 2: Equiviscous temperature ranges.

Table 3. Aging indices for short-term aged samples at different temperatures and at $1.59 \mathrm{~Hz}$.

Table 4. Aging indices for long-term aged samples at different temperatures and at $1.59 \mathrm{~Hz}$.

Table 5: Element analyze for the series of B50/70 before and after aging. 
Table 1: Viscosity measurements.

\begin{tabular}{|c|c|c|c|c|c|c|c|c|c|}
\hline \multirow{2}{*}{ Sample } & \multicolumn{3}{|c|}{ Viscosity at $105^{\circ} \mathrm{C}$ (c-P) } & \multicolumn{3}{|c|}{ Viscosity at $135^{\circ} \mathrm{C}(\mathrm{c}-\mathrm{P})$} & \multicolumn{3}{|c|}{ Viscosity at $165^{\circ} \mathrm{C}(\mathrm{c}-\mathrm{P})$} \\
\hline & o & $r$ & $\mathrm{r} / \mathrm{o}$ & o & $r$ & r/o & o & $r$ & $\mathrm{r} / \mathrm{o}$ \\
\hline B50/70 & 2675 & 4004 & 1.49 & 463 & 646 & 1.39 & 150 & 175 & 1.16 \\
\hline B50/70+10\%GS & 1592 & 3613 & 2.26 & 250 & 558 & 2.23 & 100 & 167 & 1.67 \\
\hline $\mathrm{B} 50 / 70+20 \% \mathrm{GS}$ & 1600 & 2513 & 1.57 & 213 & 388 & 1.82 & 63 & 125 & 1.98 \\
\hline $\mathrm{B} 50 / 70+30 \% \mathrm{GS}$ & 1975 & 4842 & 2.45 & 263 & 404 & 1.53 & 63 & 104 & 1.65 \\
\hline B50/70+40\%GS & 2067 & 4796 & 2.32 & 250 & 421 & 1.68 & 81 & 125 & 1.54 \\
\hline B50/70+50\%GS & 1913 & UR* & - & 213 & 933 & 4.38 & 69 & 208 & 3.01 \\
\hline
\end{tabular}

Note: $o$ and $r$ representing original age and short-term aging respectively and UR: Unreadable viscosity measurement (over 12500c-P). 
Table 2: Equiviscous temperature ranges.

\begin{tabular}{c|c|c|c|c|c|c|c}
\multirow{2}{*}{$\begin{array}{c}\text { SHRP } \\
\text { Requirements }\end{array}$} & $\begin{array}{c}\text { Amount of } \\
\text { GS }\end{array}$ & Free $(0 \%)$ & $10 \%$ & $20 \%$ & $30 \%$ & $40 \%$ & $50 \%$ \\
\cline { 2 - 8 } & $\begin{array}{c}\text { Viscosity } \\
(\mathrm{C}-\mathrm{P})\end{array}$ & $\begin{array}{c}\text { Temperature } \\
\left({ }^{\circ} \mathrm{C}\right)\end{array}$ & $\begin{array}{c}\text { Temperature } \\
\left({ }^{\circ} \mathrm{C}\right)\end{array}$ & $\begin{array}{c}\text { Temperature } \\
\left({ }^{\circ} \mathrm{C}\right)\end{array}$ & $\begin{array}{c}\text { Temperature } \\
\left({ }^{\circ} \mathrm{C}\right)\end{array}$ & $\begin{array}{c}\text { Temperature } \\
\left({ }^{\circ} \mathrm{C}\right)\end{array}$ & $\begin{array}{c}\text { Temperature } \\
\left({ }^{\circ} \mathrm{C}\right)\end{array}$ \\
\hline Mixing Range & 150 & 163.55 & 151.65 & 144.62 & 146.57 & 149.10 & 146.02 \\
$(170 \pm 20)$ & 190 & 157.62 & 145.95 & 139.94 & 142.10 & 144.30 & 141.43 \\
\hline Compaction Range & 250 & 151.01 & 139.61 & 134.70 & 137.09 & 138.91 & 136.29 \\
$(280 \pm 30)$ & 310 & 146.01 & 134.83 & 130.74 & 133.28 & 134.84 & 132.39
\end{tabular}


Table 3. Aging indices for short-term aged samples at different temperatures and at $1.59 \mathrm{~Hz}$.

\begin{tabular}{lllll}
\hline \multicolumn{5}{c}{$\begin{array}{c}\text { Short-term aging indices (G }{ }_{\text {RTFOT }} / G^{*}{ }_{\text {UnAGED }} \text { ) } \\
\text { at temperature }\end{array}$} \\
\hline Sample & $25^{\circ} \mathrm{C}$ & $30^{\circ} \mathrm{C}$ & $40^{\circ} \mathrm{C}$ & $50^{\circ} \mathrm{C}$ \\
\hline $50 / 70$ Bitumen & 0.44 & 1.19 & 1.72 & 2.61 \\
$50 / 70+10 \% G S$ & 2.07 & 1.85 & 1.09 & 3.41 \\
$50 / 70+20 \% G S$ & 9.12 & 4.51 & 2.57 & 4.87 \\
$50 / 70+30 \% G S$ & 0.57 & 0.72 & 0.80 & 1.98 \\
$50 / 70+40 \% G S$ & 2.01 & 6.96 & 1.91 & 1.65 \\
$50 / 70+50 \% G S$ & 5.54 & 3.62 & 2.02 & 3.93 \\
\hline
\end{tabular}

https://mc06.manuscriptcentral.com/cjce-pubs 
Table 4. Aging indices for long-term aged samples at different temperatures and at $1.59 \mathrm{~Hz}$.

\begin{tabular}{lccccc}
\hline \multicolumn{5}{c}{$\begin{array}{c}\text { Long-term aging indices (G* } \\
\text { at temperature }\end{array}$} \\
\hline Sample & $25^{\circ} \mathrm{C}$ & $30^{\circ} \mathrm{C}$ & $40^{\circ} \mathrm{C}$ & $50^{\circ} \mathrm{C}$ \\
\hline $50 / 70$ Bitumen & 0.72 & 2.17 & 1.58 & 5.98 \\
$50 / 70+10 \% G S$ & 3.22 & 1.59 & 1.30 & 14.98 \\
$50 / 70+20 \% G S$ & 0.85 & 1.27 & 3.39 & 11.17 \\
$50 / 70+30 \% G S$ & 2.00 & 3.08 & 0.91 & 3.71 \\
$50 / 70+40 \% G S$ & 1.08 & 5.35 & 2.09 & 2.73 \\
$50 / 70+50 \% G S$ & 1.10 & 1.85 & 5.54 & 12.34 \\
\hline
\end{tabular}


Table 5: Element analyze for the series of $\mathrm{B} 50 / 70$ before and after aging.

\begin{tabular}{|c|c|c|c|c|}
\hline Sample & Stage & Element & $\begin{array}{c}\text { Weight } \\
(\%)\end{array}$ & $\begin{array}{c}\text { Atomic } \\
(\%)\end{array}$ \\
\hline \multirow{6}{*}{ 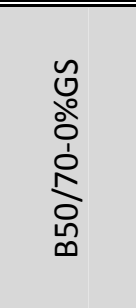 } & \multirow{2}{*}{ Un-aged } & Carbon & 100 & 100 \\
\hline & & Sulphur & - & - \\
\hline & \multirow{2}{*}{ RTFOT-aged } & Carbon & 100 & 100 \\
\hline & & Sulphur & - & - \\
\hline & \multirow{2}{*}{ PAV-aged } & Carbon & 100 & 100 \\
\hline & & Sulphur & - & - \\
\hline \multirow{6}{*}{ 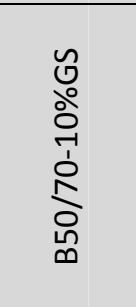 } & \multirow{2}{*}{ Un-aged } & Carbon & 91.09 & 96.47 \\
\hline & & Sulphur & 8.91 & 3.53 \\
\hline & \multirow{2}{*}{ RTFOT-aged } & Carbon & 72.98 & 87.82 \\
\hline & & Sulphur & 27.02 & 12.18 \\
\hline & \multirow{2}{*}{ PAV-aged } & Carbon & 94.39 & 97.82 \\
\hline & & Sulphur & 5.61 & 2.18 \\
\hline \multirow{6}{*}{ 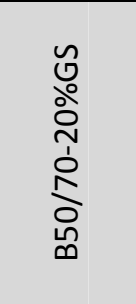 } & \multirow{2}{*}{ Un-aged } & Carbon & 82.95 & 92.85 \\
\hline & & Sulphur & 17.05 & 7.15 \\
\hline & \multirow{2}{*}{ RTFOT-aged } & Carbon & 82.83 & 92.79 \\
\hline & & Sulphur & 17.17 & 7.21 \\
\hline & \multirow{2}{*}{ PAV-aged } & Carbon & 85.40 & 93.98 \\
\hline & & Sulphur & 14.60 & 6.02 \\
\hline \multirow{6}{*}{ 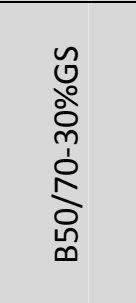 } & \multirow{2}{*}{ Un-aged } & Carbon & 70.68 & 86.55 \\
\hline & & Sulphur & 29.32 & 13.45 \\
\hline & \multirow{2}{*}{ RTFOT-aged } & Carbon & 81.33 & 92.08 \\
\hline & & Sulphur & 18.67 & 7.92 \\
\hline & \multirow{2}{*}{ PAV-aged } & Carbon & 46.83 & 70.16 \\
\hline & & Sulphur & 53.17 & 29.84 \\
\hline \multirow{6}{*}{ 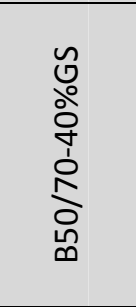 } & \multirow{2}{*}{ Un-aged } & Carbon & 68.59 & 85.36 \\
\hline & & Sulphur & 31.41 & 14.64 \\
\hline & \multirow{2}{*}{ RTFOT-aged } & Carbon & 50.99 & 73.53 \\
\hline & & Sulphur & 49.01 & 26.47 \\
\hline & \multirow{2}{*}{ PAV-aged } & Carbon & 58.87 & 79.26 \\
\hline & & Sulphur & 41.13 & 20.74 \\
\hline \multirow{6}{*}{ 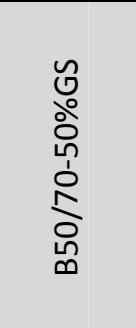 } & \multirow{2}{*}{ Un-aged } & Carbon & 92.53 & 97.06 \\
\hline & & Sulphur & 7.47 & 2.94 \\
\hline & \multirow{2}{*}{ RTFOT-aged } & Carbon & 69.91 & 86.12 \\
\hline & & Sulphur & 30.09 & 13.88 \\
\hline & \multirow{2}{*}{ PAV-aged } & Carbon & 61.29 & 80.87 \\
\hline & & Sulphur & 38.71 & 19.13 \\
\hline
\end{tabular}




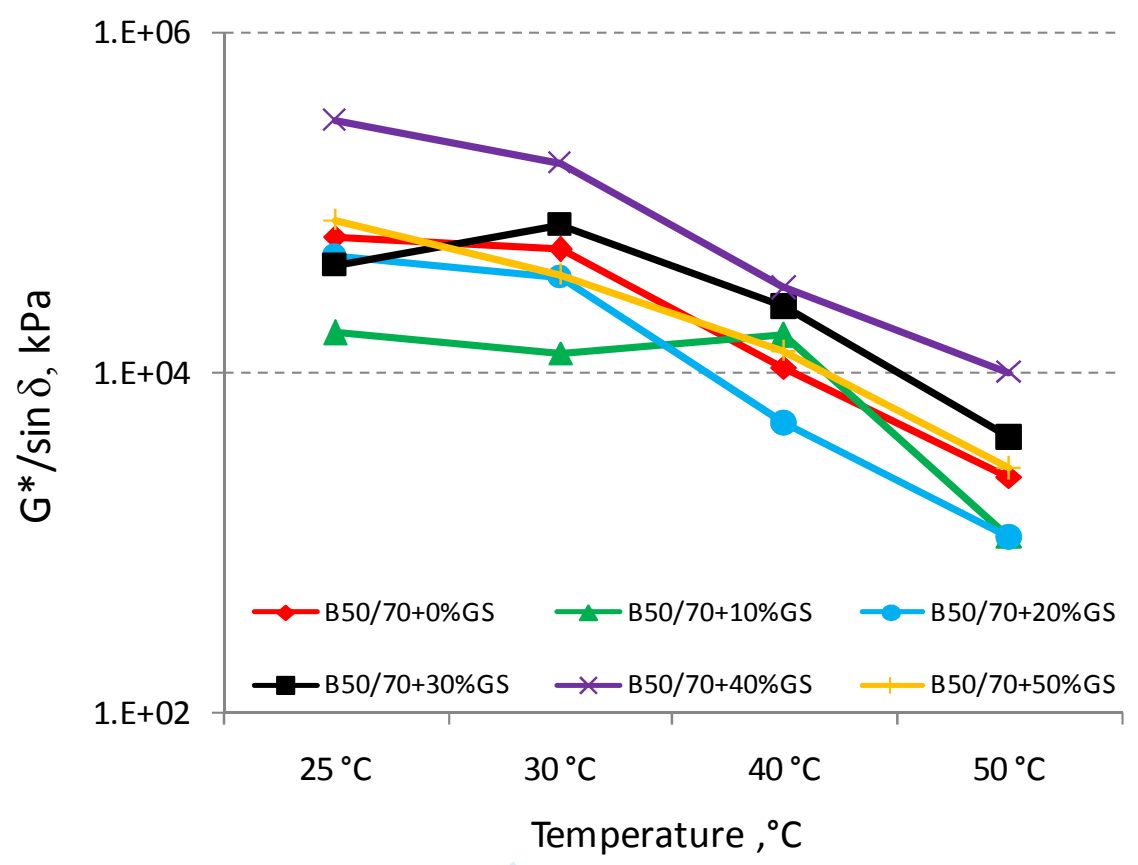

https://mc06.manuscriptcentral.com/cjce-pubs 


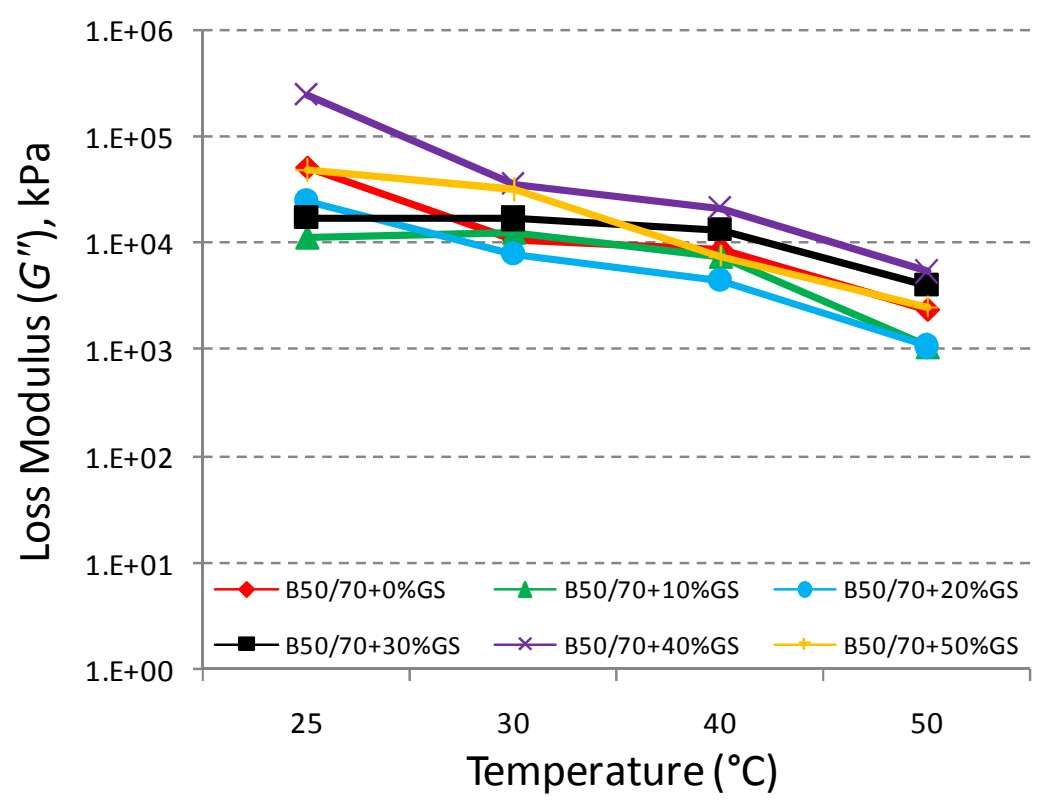

https://mc06.manuscriptcentral.com/cjce-pubs 


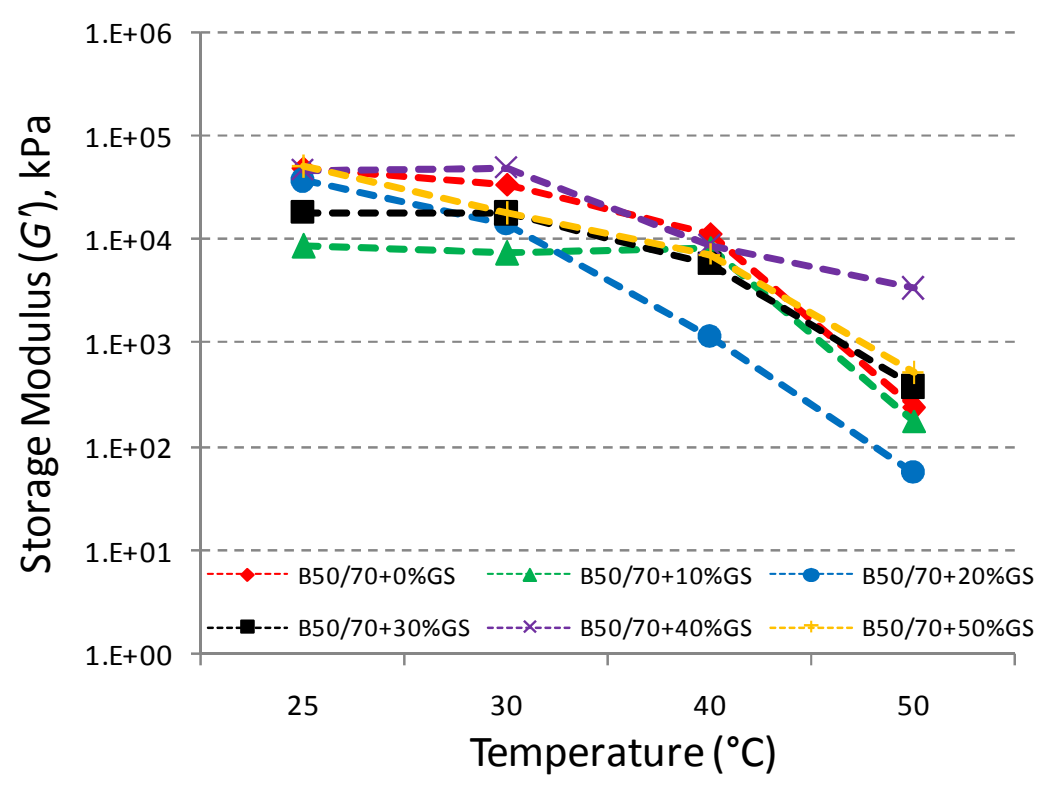

https://mc06.manuscriptcentral.com/cjce-pubs 


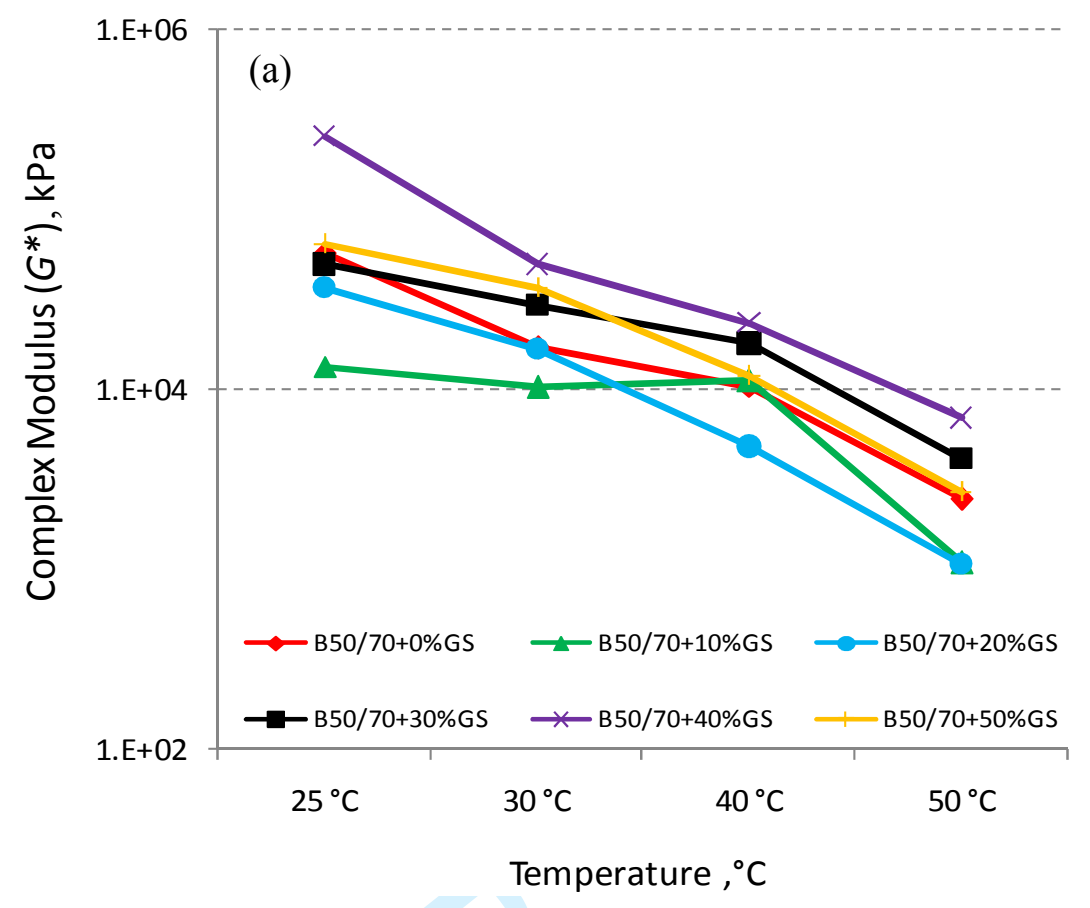

https://mc06.manuscriptcentral.com/cjce-pubs 


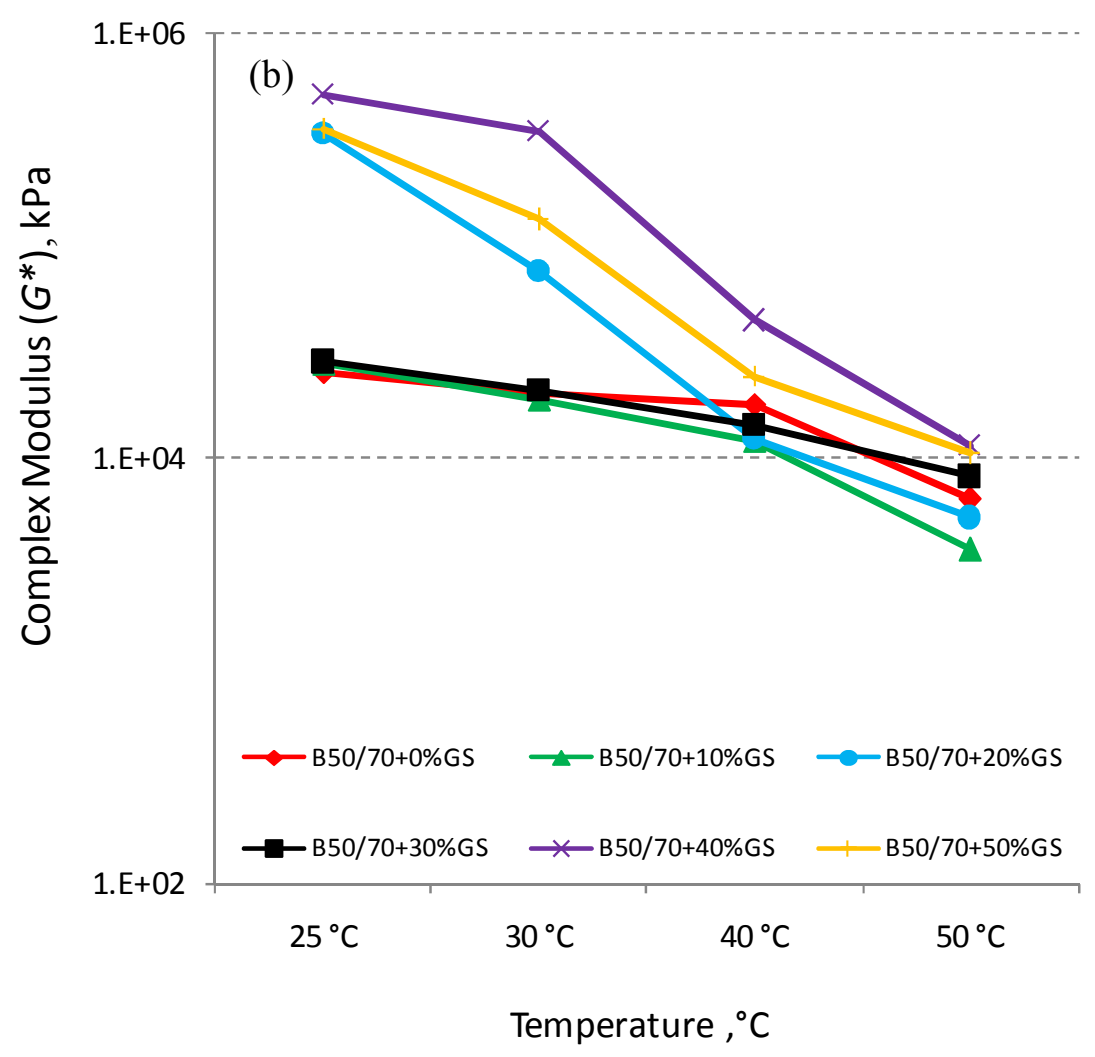

https://mc06.manuscriptcentral.com/cjce-pubs 


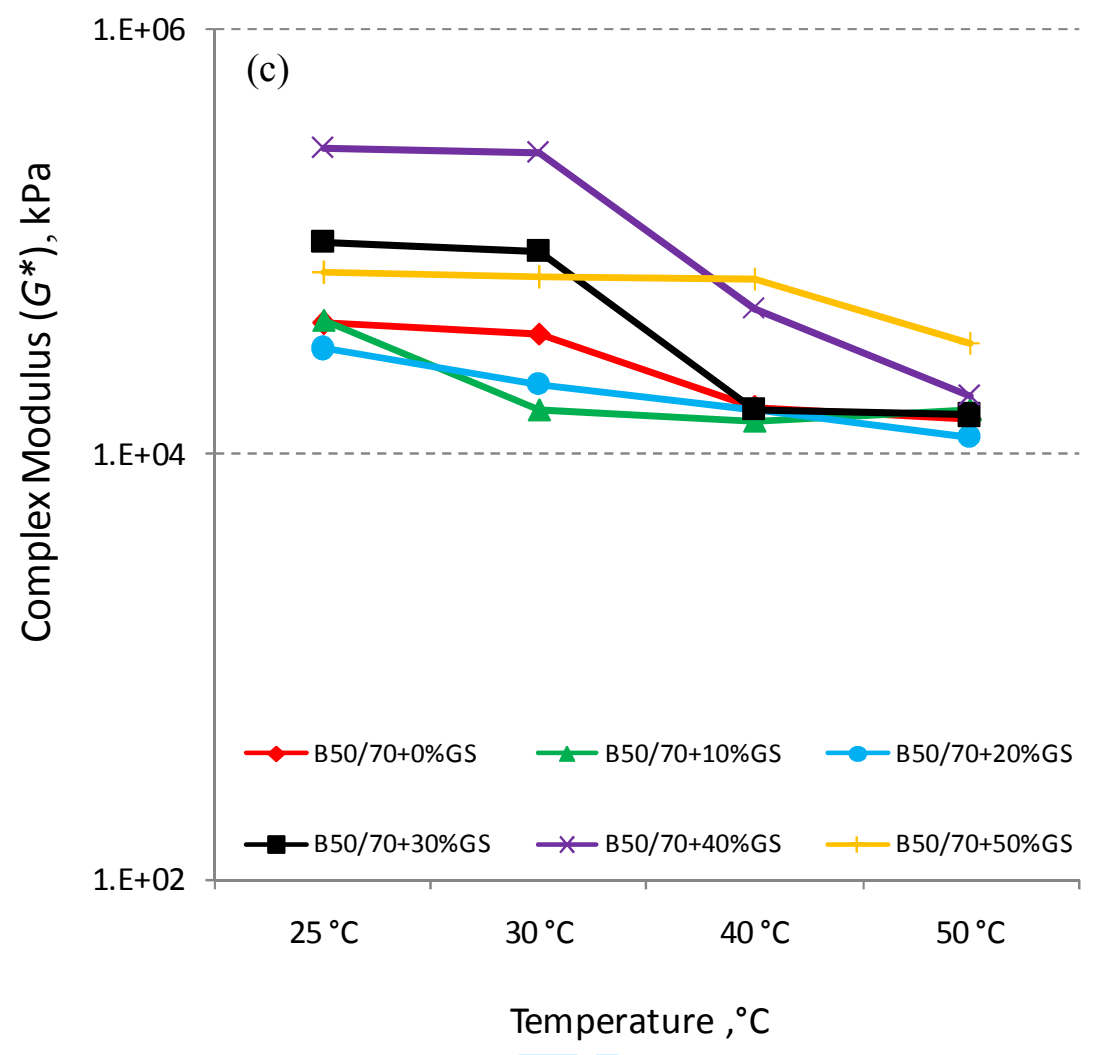

https://mc06.manuscriptcentral.com/cjce-pubs 


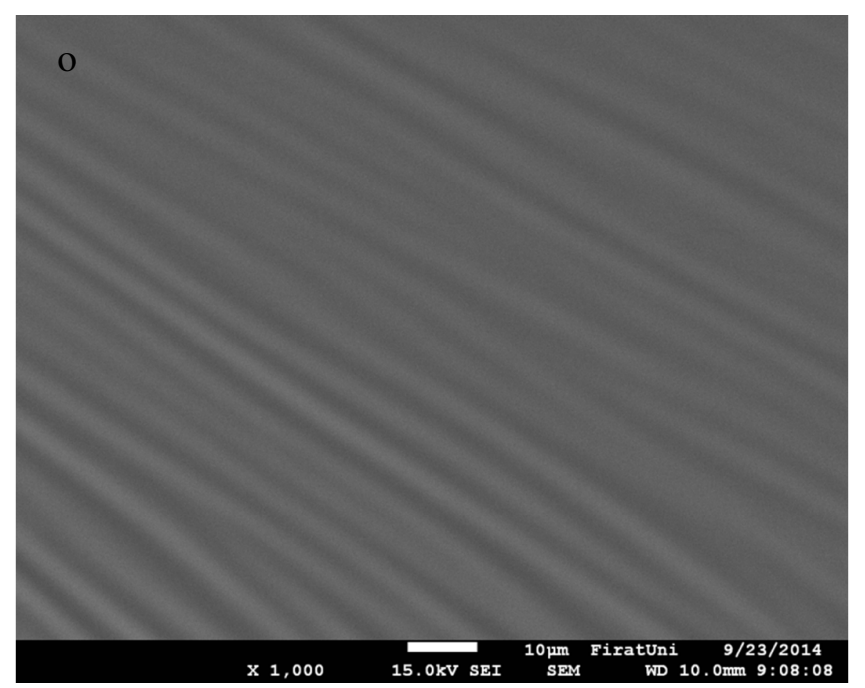

(a)

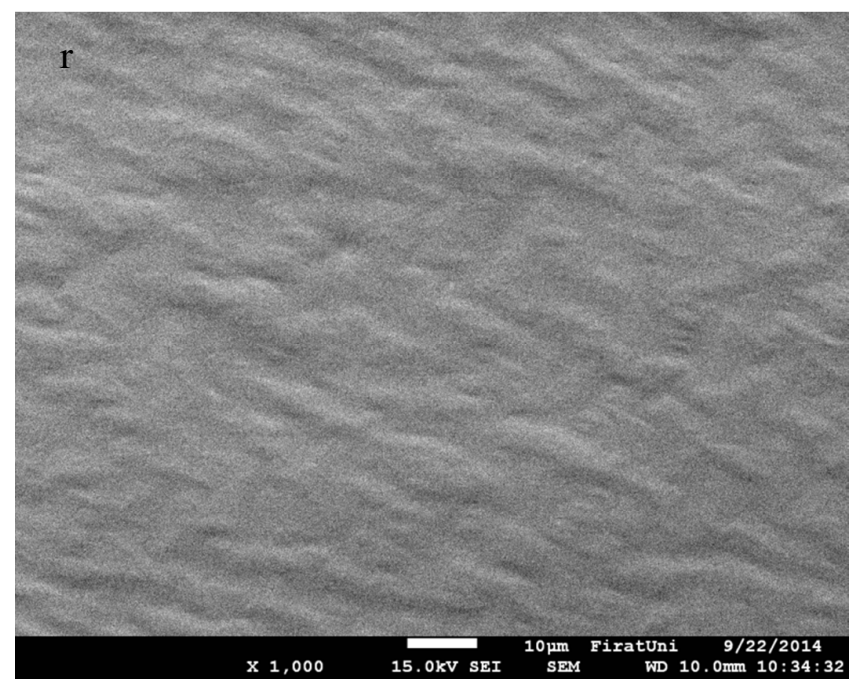

$\mathrm{p}$ 


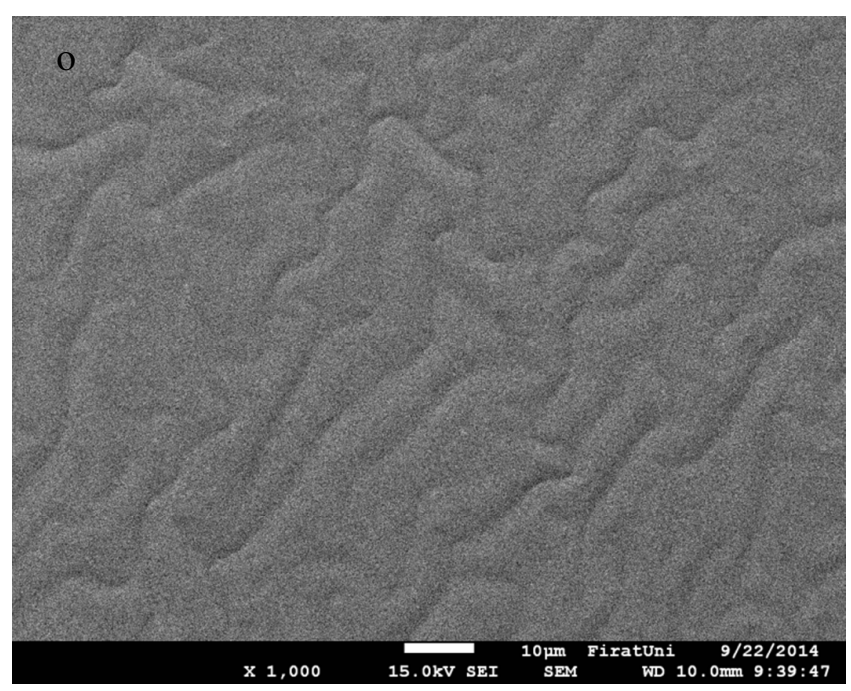

(b)
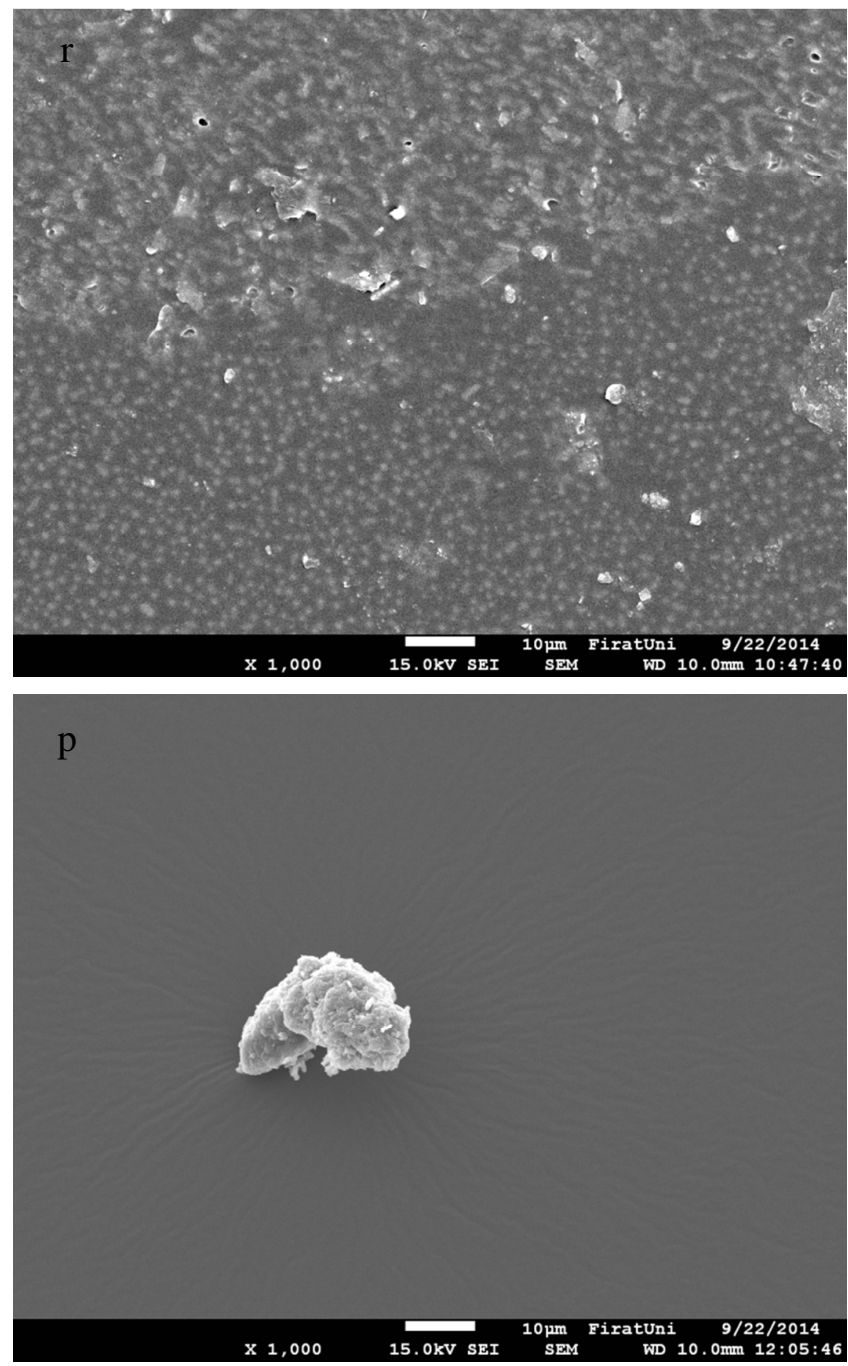

https://mc06.manuscriptcentral.com/cjce-pubs 


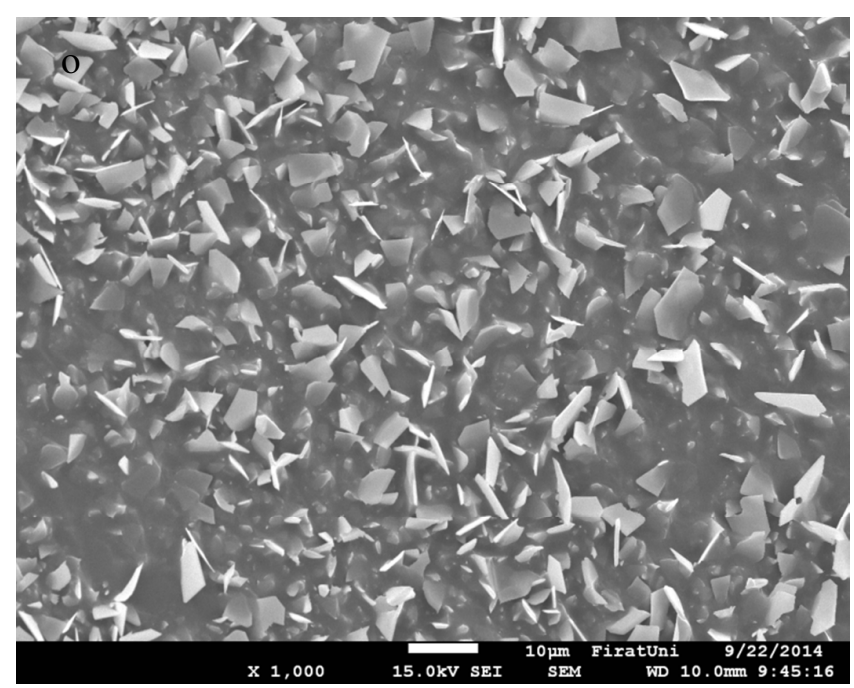

(c)
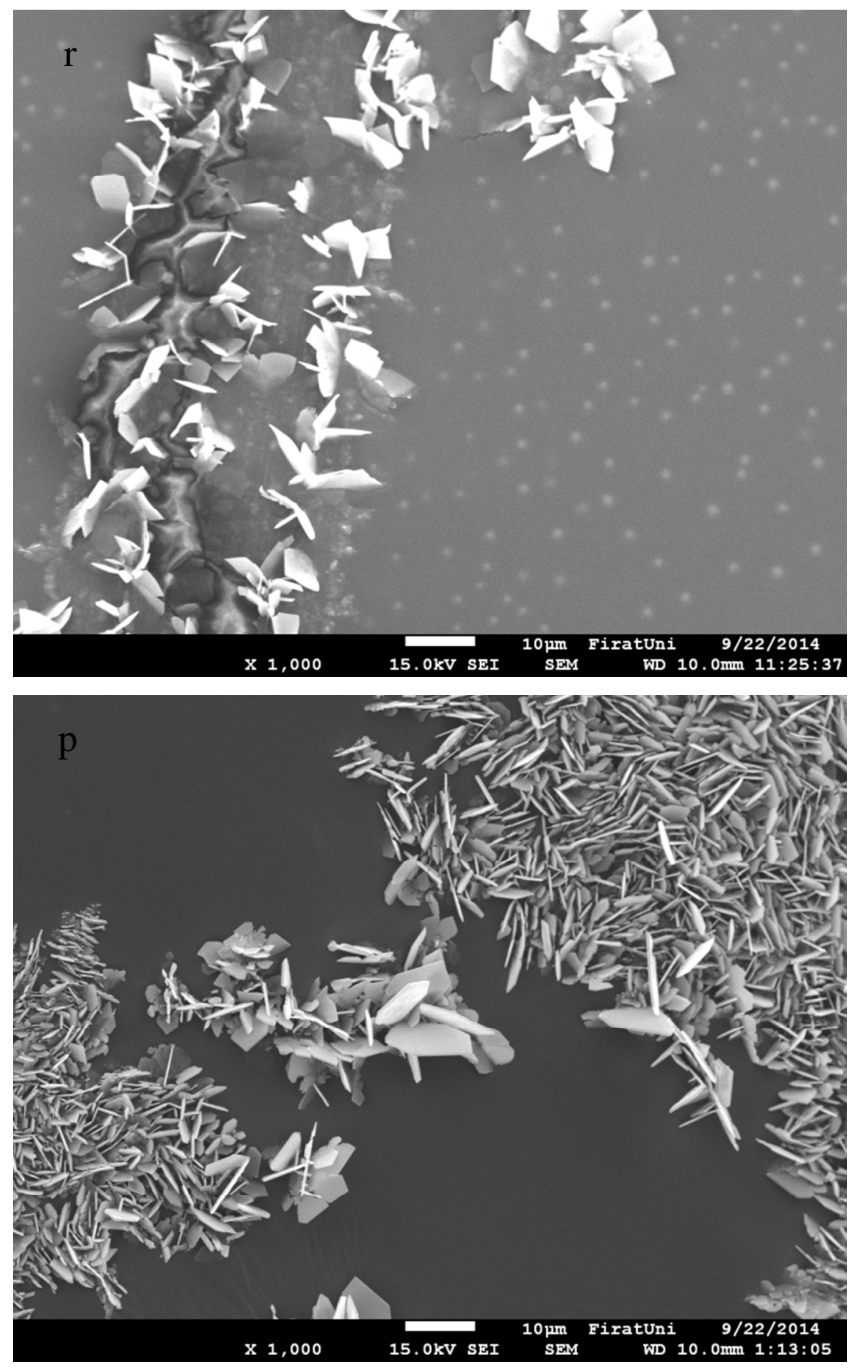


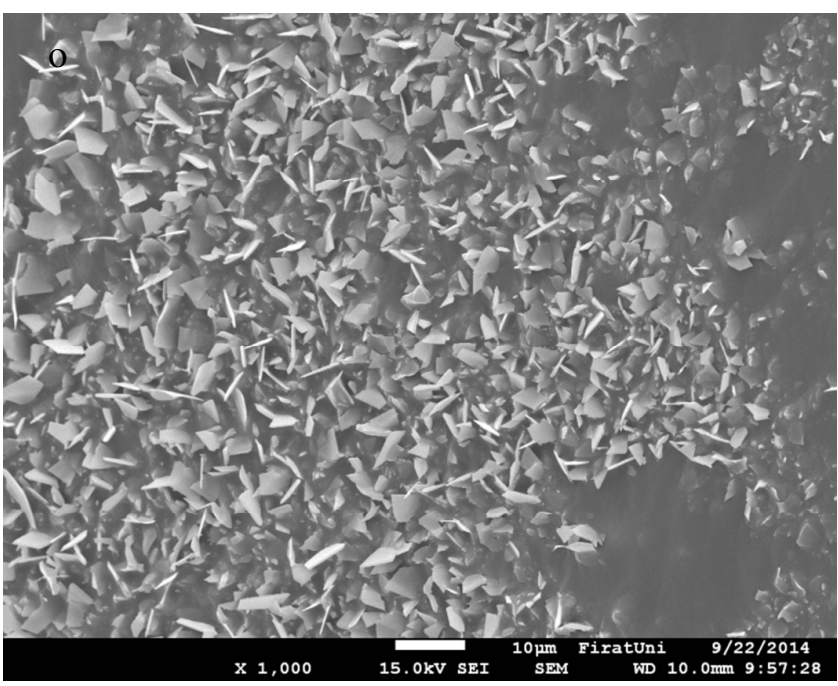

(d)
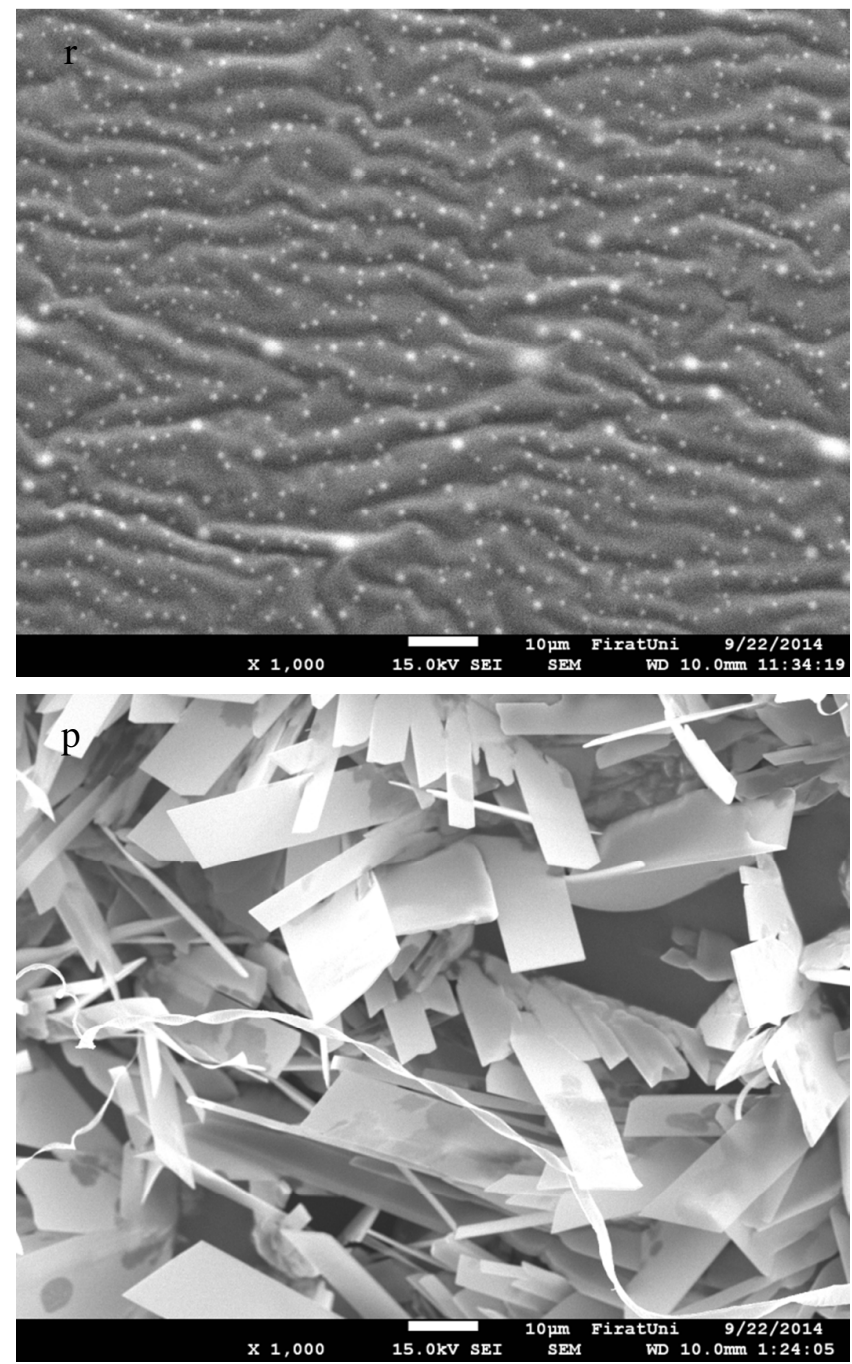


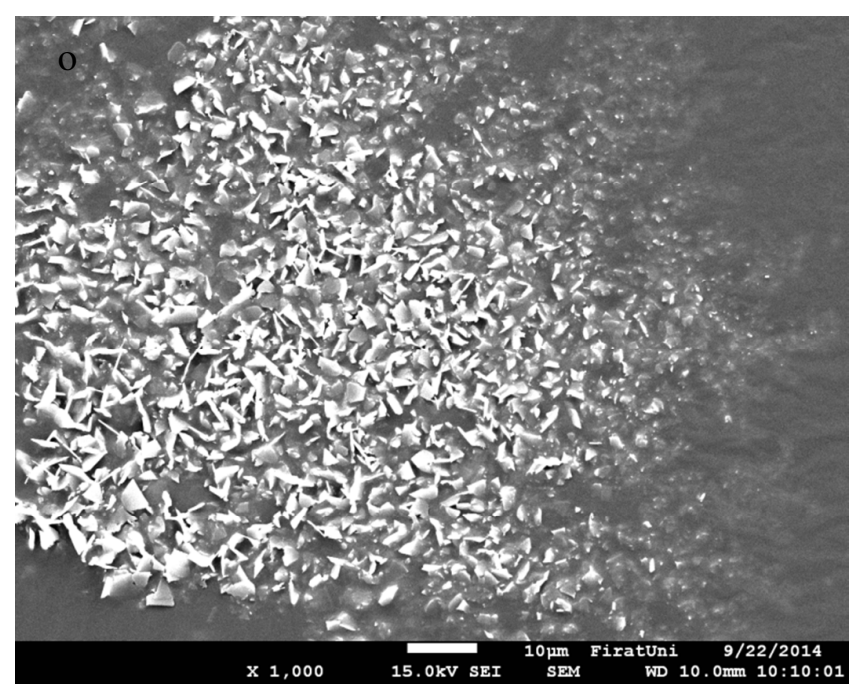

(e)
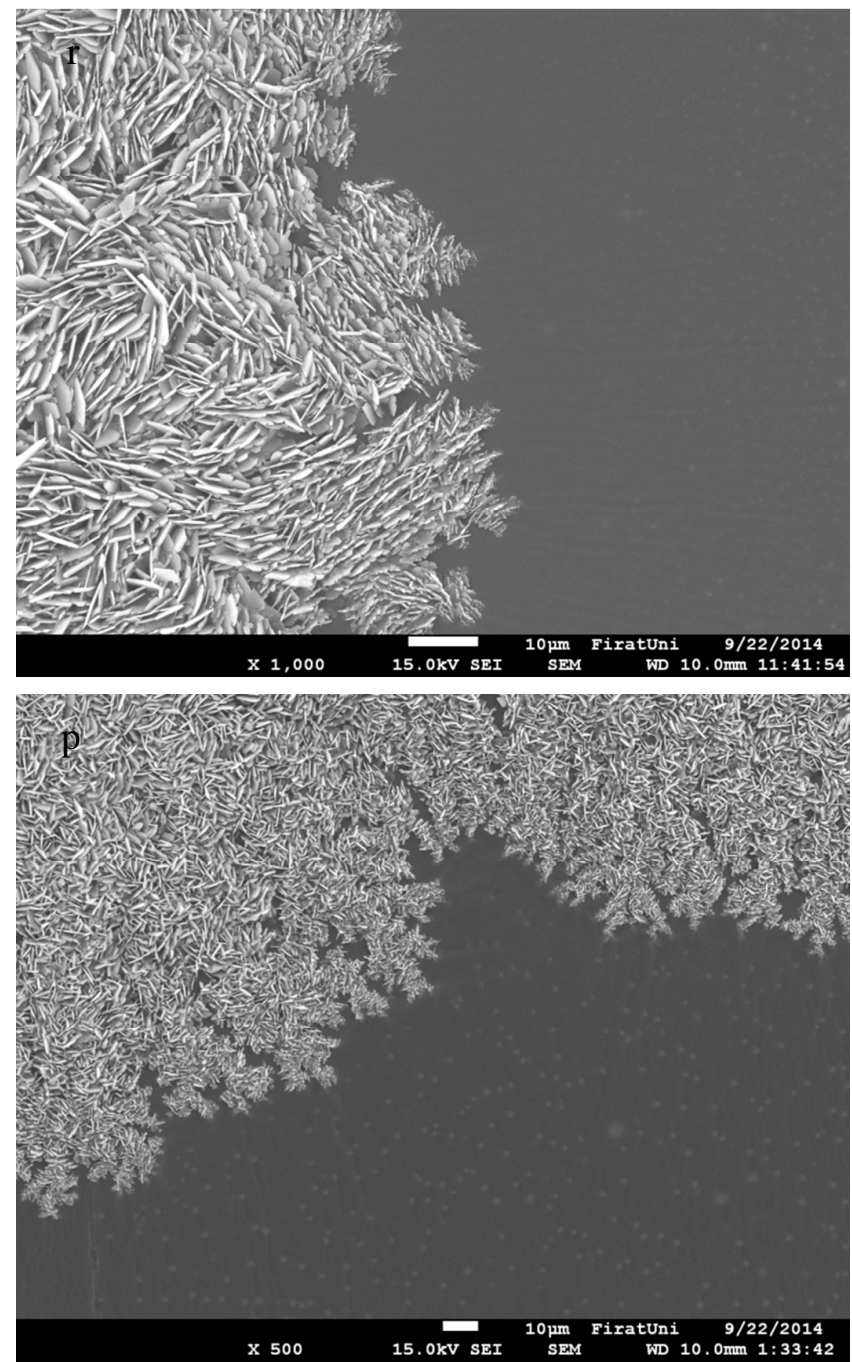


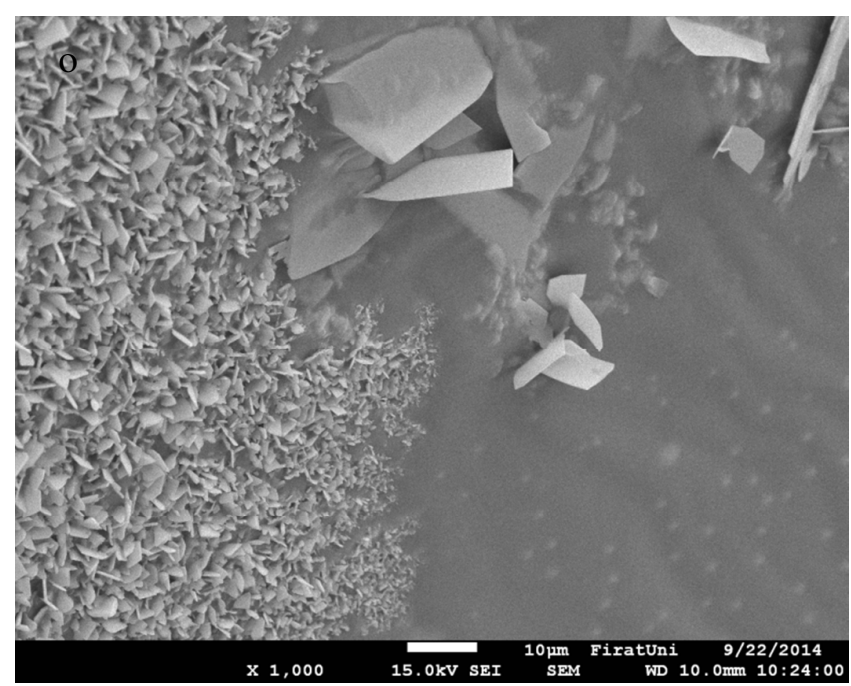

(f)
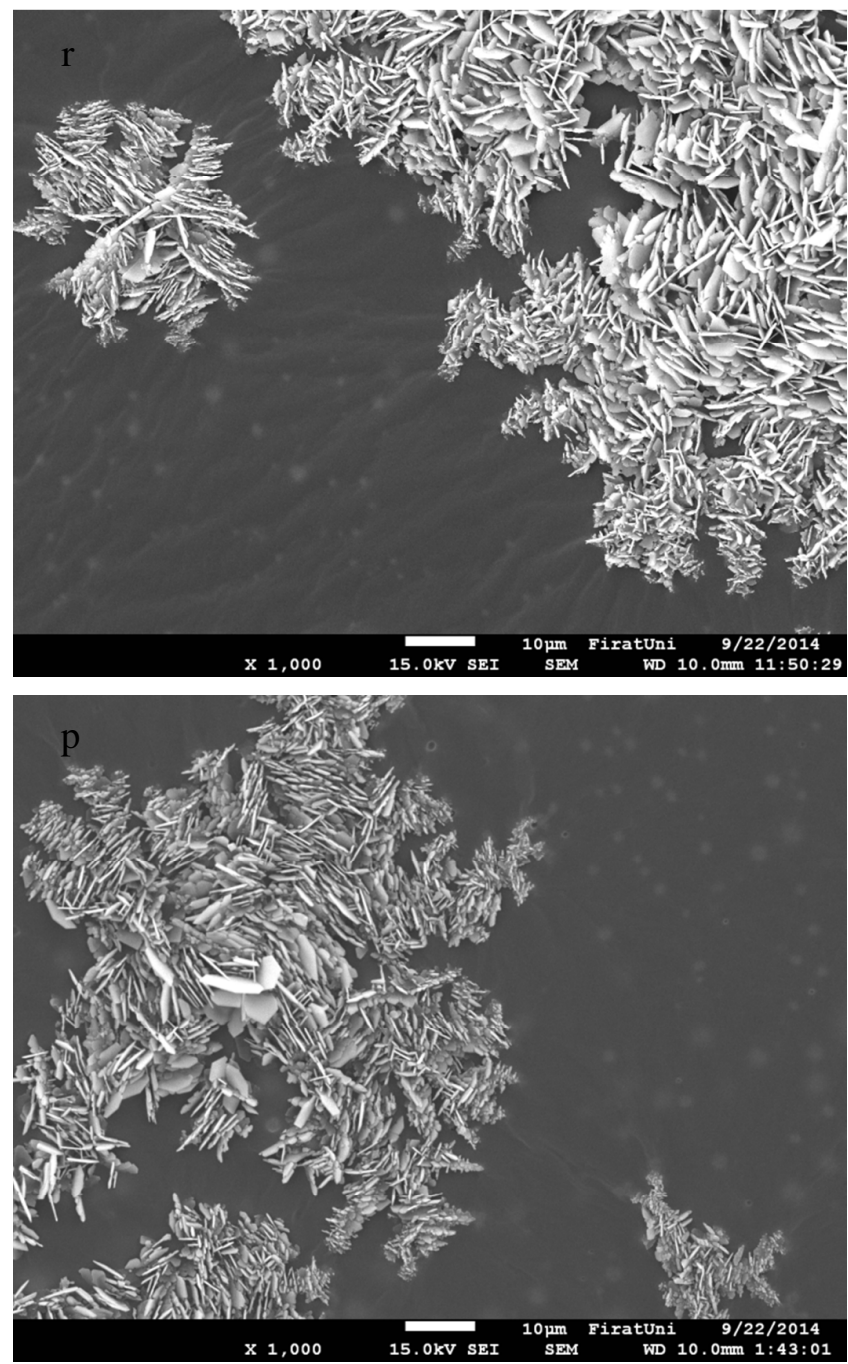